\title{
Asthma therapy: how far have we come, why did we fail and where should we go next?
}

\author{
L.J. Janssen*,\#
}

ABSTRACT: Reversible airflow obstruction and nonspecific airway hyperresponsiveness are: 1) the two key features of asthma; 2) the primary concern for asthma patients; and 3) both directly caused by the airway smooth muscle (ASM). As such, controlling bronchoconstriction should be of primary importance. Unfortunately, all existing pharmacological asthma therapies that specifically target the ASM are based on decades old strategies.

In the present study, the evolution of pharmacological asthma therapy will be briefly discussed, some explanations will be suggested as to why substantial new advances in this area have not occurred in several years and, finally, several new directions for novel asthma therapies will be proposed.

\section{KEYWORDS: Airway smooth muscle, asthma, ion channels, myosin light chain, receptors}

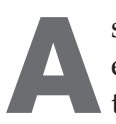
sthma affects $\sim 10 \%$ of the population and exerts a taxing drain on the economy. The three key features of this disease comprise airway inflammation, reversible airflow obstruction, and nonspecific airway hyperresponsiveness. Although it can be said that the first of these features causes the other manifestations of the disease, it has also been insightfully pointed out that "if airway inflammation didn't cause bronchospasm, asthma might be a tolerable disease" [1]. As such, the airway smooth muscle (ASM) has always been an important, yet elusive, target in the therapy of asthma, and many important and useful gains were made in this respect prior to the end of the 21st Century. Nonetheless, this disease continues to be a clinically important problem, partly due to noncompliance on the part of the patient, but also because bronchoconstriction and airway hyperresponsiveness remain beyond our complete control. However, no substantially new approach to the treatment of asthma by targeting the ASM has been developed in the last several decades. The present study will briefly summarise the gains that have been made to date in this area (for the sake of brevity, the equally important area pertaining to controlling airway inflammation will not be considered), consider some of the reasons why this important clinical problem has not been solved, and propose several novel targets which may prove useful in conquering this disease.

\section{HOW FAR HAVE WE COME?}

Over the course of many centuries, several substances have come to be associated with the relief of asthma; the basis for holding on to this association has not always been necessarily scientific. In some cases, the evidence was derived empirically: some of the compounds have real and discernible pharmacological properties, and an astute correlation was made between consumption and improvement of symptoms. For example, the plant Stromonium has been used probably due to its antimuscarinic properties, while other compounds contain methylxanthines (coffee, tea) similar to theophylline, and yet others have sedative properties (opium, chloroform, ether). Nicotine-containing plants such as tobacco and Lobelia daturum (sometimes referred to as asthma weed) have also been used. Indian hemp or Apocynum cannabinum is rich in cardiac glycosides and may be partially effective against asthma because of the downstream effects of the latter on reversemode sodium-calcium exchange activity (this will be discussed later). In other cases, the improvement might have been nothing more than a placebo effect, which is known to be a
AFFILIATIONS

*Firestone Institute for Respiratory Health, St. Joseph's Hospital, and \#Dept of Medicine, McMaster University, Hamilton, ON, Canada.

CORRESPONDENCE

L.J. Janssen

L-314

St. Joseph's Hospital

50 Charlton Ave. East Hamilton

ON

L8N 4A6 Canada

Fax: 9055406510

E-mail: janssenl@mcmaster.ca

Received:

May 022008

Accepted after revision:

October 152008

SUPPORT STATEMENT

This study was supported by operating funds provided by the Canadian Institutes of Health

Research (Ottawa, ON, Canada).

STATEMENT OF INTEREST

A statement of interest for

L.J. Janssen can be found at

www.erj.ersjournals.com/misc/

statements.shtml 
powerful confounder with which all well-designed clinical studies must now contend.

Around the beginning of the last century, doctors began to apply the scientific method to this problem, identifying the variables involved, then proposing and testing hypotheses, from which real and substantial gains were made. For example, it was soon recognised that the primary excitatory innervation to the airways is cholinergic in nature, that the airways are also under the strong influence of inflammatory mediators (particularly histamine and leukotrienes (LTs)) released from inflammatory cells residing in the airway walls, and that adrenergic compounds exert an inhibitory (relaxant) effect, in part through an action on the classical cyclic nucleotide signalling pathway (fig. 1). Armed with this fundamental knowledge of the external inputs to the airways, it was possible to develop five major classes of drugs: 1) anticholinergics; 2) antihistamines; 3) antileukotrienes; 4) $\beta$ agonists and 5) phosphodiesterase (PDE) inhibitors. These five diverse classes of drugs, together with steroids which address the inflammatory aspect of asthma, have formed the mainstay of our armamentarium against asthma, and the past several decades have only seen modifications of these tools, with the goal of merely making them more selective and/or longer lasting.

Despite having and continually refining these complementary and powerful pharmacological approaches, asthma is still not completely controlled. We still contend with exacerbations of symptoms. Although this is, in part, related to lack of compliance, even patients who carefully employ these agents still suffer from airflow obstruction. This raises the question, why have we failed? To ponder the answers to this question is not merely an academic exercise: it is believed that lessons can be learnt which will guide future endeavours to better control asthma.

\section{WHY HAVE WE FAILED?}

\section{Current therapies are too specific}

As outlined previously, the major excitatory inputs to the ASM comprise acetylcholine, histamine and the LTs, each acting through distinct high-affinity receptors (fig. 1). As such, blockers were developed which would interfere with their binding to those receptors. The first of these was the anticholinergic group of drugs, beginning with those which blocked muscarinic receptors nonselectively: these were progressively refined to be more selective for muscarinic $\mathrm{M}_{2}$ or $\mathrm{M}_{3}$ receptors and/or to be longer lasting. The antimuscarinics were followed by agents that blocked the actions of histamine: first those which were nonselective between the histamine receptors, and then refined to be more selective for the histaminergic $\mathrm{H}_{1}$-receptors in particular. More recently, we have seen the development of the antileukotrienes, which are both receptor blockers and synthesis inhibitors: these were primarily developed to address the inflammation seen in asthma, but would nonetheless ameliorate the excitatory actions of these drugs on the ASM. As with the previous two classes of drugs, the first LT receptor blockers were nonselective between the LT receptor sub-types, and were later refined to be more selective for the cys- $\mathrm{LT}_{1}$ receptor.

In all three cases, these receptor blockers are highly selective against the action of only one ligand, and were refined to specifically target the receptors present on the ASM (or, in the

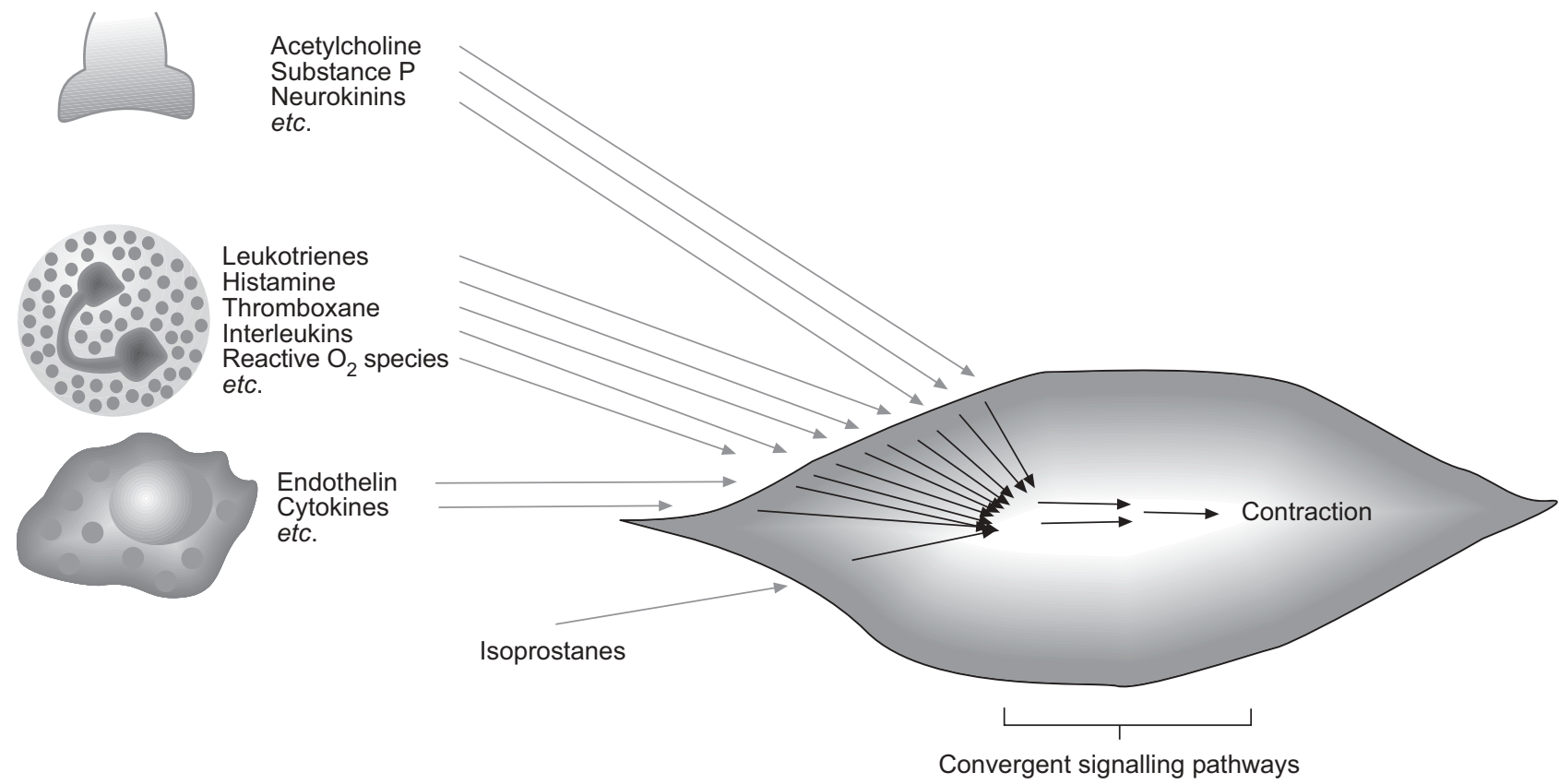

FIGURE 1. The airway smooth muscle cell receives multiple excitatory and inhibitory inputs, each of which act through a distinct plasmalemmal receptor; many current asthma therapies are based on blocking or mimicking these individually at the receptor level (using anticholinergics, antihistamines, antileukotrienes, $\beta$-agonists). However, these inputs all terminate on a common set of signalling events: a "convergent signalling pathway". This commonality may explain, in part, the nonspecific nature of airway hyperresponsiveness, which is a key feature of asthma. More importantly, it may be more generally useful to target one or more steps in the convergent signalling pathway and thereby treat bronchoconstriction imposed by any/all excitatory input. 
case of the antileukotrienes, the inflammatory cells) while sidestepping receptors for those same ligands on other cell types. Pharmacologically, this is an excellent strategy; however, we now know that the airways are excited by a very wide range of autacoids. There are other neurotransmitters, including neuropeptides such as substance $P$, neurokinins, etc. (fig. 1). The inflammatory cells release a wide range of autacoids other than histamine and leukotrienes, which exert excitatory actions on the ASM, including thromboxanes, cytokines (interleukins, tumour necrosis factor- $\alpha$ ), reactive oxygen species, etc. Cytokines and reactive oxygen species are also released from the epithelium, along with other excitatory autacoids such as endothelin. The reactive oxygen species which arise from these two cellular sources, as well as the general condition of oxidative stress seen in asthma, lead to the production of isoprostanes: peroxidative metabolites of membrane lipids [2]. While isoprostanes have long been used as markers of oxidative stress, they are now known to exert powerful biological responses on a wide variety of cell types, including excitation of ASM via action on thromboxane receptors [2-4]. Growth factors released by these cells have also been shown to evoke constrictor responses.

To fully protect the ASM against excitatory input using the pharmacological strategy first employed against asthma (i.e. receptor blockade), other receptor blockers would need to be developed for each of these excitatory autacoids, leading to a dizzying array of therapeutic molecules that would continually expand as new mediators are always being discovered. Clearly, receptor blockers are not the final answer to the treatment of asthma.

\section{We borrowed too heavily from other fields without doing our own homework}

Several times in the past, developments in the ASM/asthma field have been seen following those made in other areas, most often in the cardiovascular field given that airway and arterial smooth muscle preparations act in a similar fashion (on certain levels). However, in many ways, the two preparations are quite different, and scientists in the airway field can be misled by developments made in other areas. This is best exemplified by the voltage-dependent $\mathrm{Ca}^{2+}$ channel blockers. As researchers sought to understand the mechanisms underlying vasoconstriction, they identified a key step which was involved in the response to many autacoids: influx of external $\mathrm{Ca}^{2+}$ through voltage-dependent $\mathrm{Ca}^{2+}$ channels. As such, they were able to develop highly selective and potent blockers of the channels that mediate this influx. These have since become a mainstay in the treatment of hypertension. Subsequently, the very same type of channel (L-type $\mathrm{Ca}^{2+}$ channels) was found in ASM, with the exact same biophysical and pharmacological properties. Moreover, bronchoconstrictor agents were found to depolarise the ASM membrane while bronchodilators hyperpolarised it. Thus, it seemed self-evident that the same class of $\mathrm{Ca}^{2+}$-channel blockers would prove to be effective against asthma, and clinical studies were launched to test this hypothesis, despite the fact that pre-clinical work showed bronchoconstriction to be largely independent of voltagedependent mechanisms and to be insensitive to $\mathrm{L}$-type $\mathrm{Ca}^{2+}$ channel blockers. The clinical studies soon concluded that these drugs were relatively ineffective against asthma [5-11].
The physiological role(s) for these abundantly expressed channels is as yet unclear, but may relate to regulation of gene expression, proliferation or apoptosis [12]. Despite this negative finding, asthma research soon shifted focus toward $\mathrm{K}^{+}$channel openers, which were concurrently being developed and found to be useful in hypertension. Although the mechanism of action of these newer agents was essentially the same as the L-type $\mathrm{Ca}^{2+}$ channel blockers, rather than blocking the open $\mathrm{Ca}^{2+}$ channels, $\mathrm{K}^{+}$channel openers hyperpolarise the membrane in order to prevent the $\mathrm{Ca}^{2+}$ channels from opening. After much effort and precious research funding, it was concluded (not surprisingly) that $\mathrm{K}^{+}$channel openers were also not useful against asthma [13-16]

The lesson to be learned from this is that we should not look for short-cuts through the field of cardiovascular research (or work being carried in other fields), but clinical studies must be firmly based on the pre-clinical work performed using airway tissues. However, this mistake continues to be made. For example, as will be shown later, myosin light chain kinase (MLCK) could prove to be an exceedingly tantalising novel target in the efforts to control asthma if a way to exploit the differences between MLCK in airway and pulmonary vascular smooth muscles could be found. Unfortunately, almost nothing has been specifically learnt about MLCK in ASM, presumably because it is felt that we already know about MLCK from the work performed in the vascular fields. The same point could be made for many of the other novel targets presented below.

\section{We became lazy: too much of the pre-clinical work was not performed in an optimal fashion}

The point that more research needs to be carried out using airway tissues has been made previously. However, even the basic studies that are already being performed using those airway tissues may not be carried out in the most clinically relevant way: too much of the pre-clinical work has been based on cholinergic responses in tracheal preparations, too often using supra-maximal concentrations of agents, as elaborated below.

First, too many pre-clinical studies are carried out using tracheal smooth muscle preparations, largely because they are easier to obtain and handle than the small airways, or because it is easier to get a pure cell culture preparation without other cell types. However, there are several differences between the trachealis and smaller airways, e.g. differences related to structure, cellular composition, innervation, pharmacology, distribution of ion channels and receptors; reviewed in greater detail elsewhere $[17,18]$, and it is the small airways that are more important in physiology (determining resistance to airflow) and pathophysiology (inflammation, asthma). Related to this, cultured ASM is being used in more and more studies, even though cultured cells have long been known to exhibit markedly different phenotypes compared with their native counterparts, and control experiments are all too infrequently performed to assess how similar a given preparation of cells, let alone a given batch of that preparation, retains the relevant native properties of the original cells.

Secondly, pre-clinical studies are most often carried out using cholinergic agonists to evaluate a particular intervention. 
However, as mentioned previously, there are many other autacoids that excite ASM, and these can show markedly different pharmacological sensitivity compared with cholinergic responses. For example, the present author has found serotonin-evoked responses are sensitive to Src-kinase inhibitors while cholinergic responses appear not to be [19]. Thus, it may be that certain interventions have been tested and dismissed only because they were relatively ineffective against cholinergic responses, but might have been highly useful against other forms of bronchoconstrictor stimuli. In other words, the mistake which may have been made all along is that only cholinergic excitation is being effectively controlled, while bronchoconstriction evoked by other autacoids has escaped pharmacological/therapeutic control.

Thirdly, a great many basic pre-clinical studies are performed using overwhelming concentrations of pharmacological agents. For example, many in vitro studies are carried out to compare the responses to high-micromolar concentrations of cholinergic or adrenergic stimuli before and during some form of intervention. However, such extreme degrees of stimulation are rarely, if ever, seen in real life. Certainly sub-threshold levels of stimulation to any given autacoid are seen in both normal and asthmatic individuals, and these levels of stimulation might rise further in asthmatics than in normals, but it seems unlikely that autacoids (acetylcholine, norepinephrine, histamine, leukotrienes, endothelin, etc.) accumulate to such levels that their respective receptors become maximally stimulated. Even if it were possible for such supra-maximal levels of stimulation to be realised, previous studies have shown that only half-maximal stimulation of the ASM is sufficient to completely close the airways [20]: as such the upper half of these in vitro concentration-response relationships are physiologically irrelevant. It doesn't matter how much more tension or shortening an airway preparation can generate if half-maximal stimulation is sufficient to obstruct airflow in the intact airway. This point calls into question studies of experimentally induced airway hyperresponsiveness, which show an increase in the maximal response to a given stimulus without any real leftward shift in the concentration-response relationship for that stimulus, as is seen in human asthma, but rarely shown in animal models. However, several studies [21-24] have documented a very provocative phenomenon of "agonist synergism" in ASM, in which relatively low concentrations of one agonist markedly enhance the lower portion of the concentration-response relationship for several other agonists, but have no effect whatsoever at the upper ends of those relationships (fig. 2). This synergism has been demonstrated using acetylcholine, histamine, serotonin, adenosine triphosphate, potassium chloride and the isoprostane $15-\mathrm{E}_{2 \mathrm{t}}$-IsoP, and mimics induction of nonspecific airway hyperresponsiveness, a cardinal feature of asthma. Pharmacological blockers and inhibitors are also often tested at concentrations that are difficult or even impossible to achieve under therapeutic conditions, and are often found to reduce the maximal bronchoconstrictor response without exerting a rightward shift in the concentration-response relationship for the autacoid (the latter is needed to be useful in the treatment of asthma).

Altogether, not only is it important that more pre-clinical studies are carried out using airway tissues, but these should be performed in a more rational, relevant manner. The preclinical studies should: 1) emphasise the use of small airways (preferably human and ideally freshly derived rather than cultured); and 2) be performed using more physiologically relevant levels of stimulation (preferably including noncholinergic agonists) and/or therapeutically achievable concentrations of interventions.

\section{We stopped trying}

During the better part of the last century, asthma was considered to be an ASM-related disease, and attention was primarily focused on understanding the physiology and pharmacology of the ASM. However, the attention soon shifted to the inflammatory response. This shift in focus broadened and deepened and diverted limited resources (personnel, funding, etc.) away from the work being carried out in ASM. As a result, the latter stagnated and fell far behind parallel work being performed in the vascular field. Although inflammation is indeed a cardinal feature of asthma, so are reversible airflow obstruction and nonspecific airway hyperresponsiveness, both of which are direct products of smooth muscle function. Moreover, the latter two features are the more relevant to patients, who do not complain about the levels of inflammatory cells or mediators in their airways, but rather the fact that their airways are too constricted to allow satisfying ventilation. Unfortunately, the current treatments for asthma which target the ASM are based on decades old strategies, and no substantially new molecules have appeared on the horizon. Lately, scientists have been merely looking for variations on a theme: agents that are longer lasting or more highly selective than the original agents which were first introduced decades ago. The mechanisms underlying excitation-contraction coupling in ASM need to be better understood.

\section{WHERE DO WE GO NEXT?}

\section{The convergent signalling pathway}

The present study previously highlighted the fact that the ASM is excited by a wide variety of distinct autacoids all acting through highly selective receptors, making it impossible to fully control asthma using an approach directed at those cell surface receptors. However, an intracellular approach might be superior. Relatively recent work in the ASM field has revealed that these diverse receptors act through a common set of signalling events, opening up a far more efficient and effective approach. If we can identify and control a signalling event that is common to the various bronchoconstrictors, we could far better control bronchoconstriction evoked by any form of stimulus, and thus better control asthma (fig. 1). This convergent signalling pathway will be discussed later. A graphic representation of this summary is shown in figure 3.

In general, contraction of muscle involves the interaction between two protein filaments: actin and myosin. In the case of skeletal and cardiac muscle, these two proteins can interact directly and produce the basic features of contraction: hydrolysis of adenosine triphosphate (ATP) and translocation of one filament past another. However, in the case of smooth muscle, myosin must first be phosphorylated before this interaction can occur. This phosphorylation is catalysed by MLCK, which is in turn a $\mathrm{Ca}^{2+} /$ calmodulin-dependent 


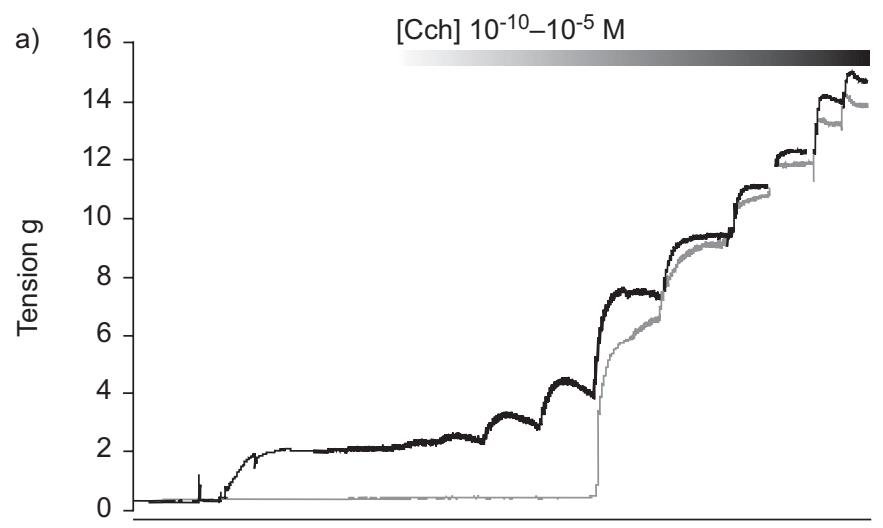

$\log [$ Cch] M

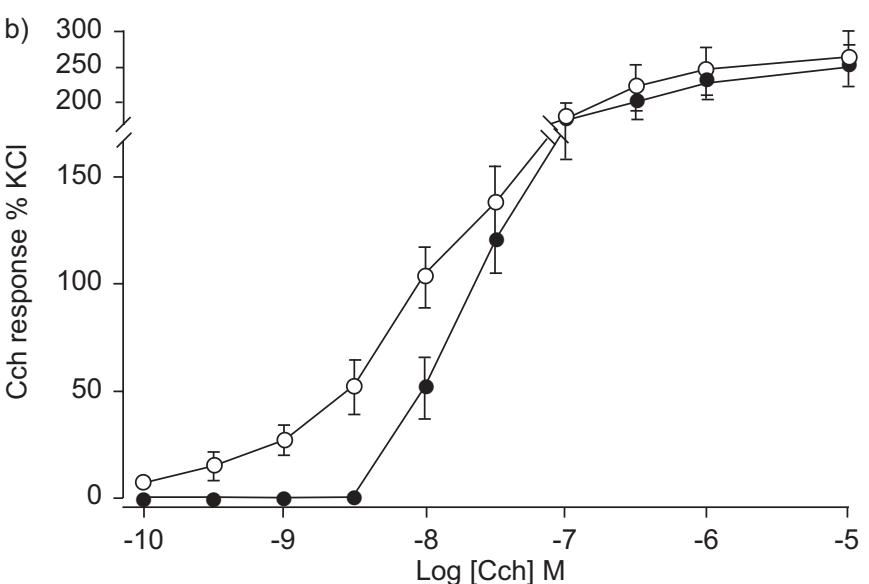

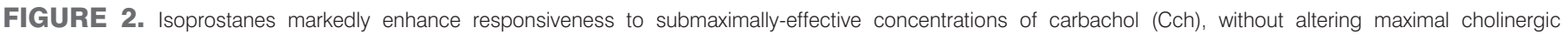

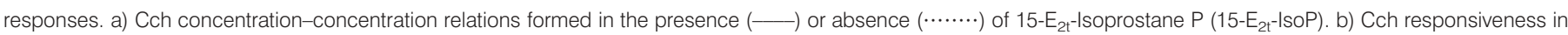
the presence $(\bigcirc)$ or absence $(\bullet)$ of $15-E_{2 t}-I s o P$. Reproduced from [21] with permission from the publisher.

enzyme: changes in cytosolic concentrations of $\mathrm{Ca}^{2+}$ are transduced into a mechanical response.

At rest, $\left[\mathrm{Ca}^{2+}\right]_{\mathrm{i}}$ is maintained at relatively low levels through the action of a $\mathrm{Ca}^{2+}$ pump on the plasmalemma (which extrudes $\mathrm{Ca}^{2+}$ out of the cell), as well as another $\mathrm{Ca}^{2+}$ pump on the sarcoplasmic reticulum (sequesters $\mathrm{Ca}^{2+}$ from the cytosol). In response to the appropriate stimulus (e.g. an autacoid ligand acting on a plasmalemmal receptor), $\left[\mathrm{Ca}^{2+}\right]_{i}$ is elevated by opening of $\mathrm{Ca}^{2+}$-permeable ion channels either on the plasmalemma or on the endoplasmic reticulum. In the past, many scientists focussed their attention on the solitary, brief, spike-like $\mathrm{Ca}^{2+}$ transient evoked by a high concentration of agonist. It is now known that agonists can often evoke recurring $\left[\mathrm{Ca}^{2+}\right]_{i}$ transients (oscillations with a frequency dependent on agonist concentration), which propagate (as long as the agonist is applied) through the cell as waves and are further shaped as they progress through the cytosol [25, 26]. The amplitudes (peak height and plateau) and frequency of the $\mathrm{Ca}^{2+}$ waves encode information, which can be decoded by cellular entities, such as $\mathrm{Ca}^{2+} /$ calmodulin-dependent kinase [27-33], MLCK [27], calpain [34], mitochondria [35] or the sarcoplasmic reticulum $\mathrm{Ca}^{2+}$-pump [27]. This decoding translates, for example, into frequency dependence of contraction $[36,37]$ or of gene transcription [38, 39]. Important advances have been made in the current understanding of the mechanisms underlying these $\mathrm{Ca}^{2+}$ oscillations. These have been described in far greater detail than is possible here [36, 37, 40, 41], and the biophysical and pharmacological properties of the cellular machines (pumps and channels) involved in triggering and propagating these $\mathrm{Ca}^{2+}$ waves have been reviewed elsewhere $[42,43]$. The present study simply introduces the various cellular entities which are involved.

In contrast to the central importance of voltage-dependent influx of $\mathrm{Ca}^{2+}$ in activation of vascular smooth muscle, the key trigger for bronchoconstriction is release of internal $\mathrm{Ca}^{2+}$ that has been sequestered within an intracellular organelle: the sarcoplasmic reticulum. Two major $\mathrm{Ca}^{2+}$-release pathways are involved, both comprise highly specialised receptor-channel complexes which are activated by binding of an intracellular signalling ligand. One is gated by inositol-1,4,5-trisphosphate (the $\mathrm{IP}_{3}$-receptor). The other is activated by cytosolic $\mathrm{Ca}^{2+}$ itself (a process referred to as $\mathrm{Ca}^{2+}$-induced $\mathrm{Ca}^{2+}$-release), but is also sensitive to the plant alkaloid ryanodine (thus often referred to as the ryanodine receptor, or RyR) or possibly also cyclic adenosine diphosphate ribose. $\mathrm{IP}_{3}$-receptors, by definition, are triggered by the phosphoinositide signalling cascade which in turn is activated by agonists acting through classical G-protein coupled receptors (e.g. acetylcholine, histamine, LT, isoprostanes, etc.). The physiological role(s) for the RyR are still under debate [44].

If $\mathrm{Ca}^{2+}$ can be released from this internal pool, there must be a pathway by which the pool can be refilled, otherwise it will rapidly become depleted and mechanical control will be disrupted. After decades of research, both in smooth muscle, in general, and ASM, in particular, only one active uptake pathway has been identified, that being the sarcoplasmic/ endoplasmic reticulum $\mathrm{Ca}^{2+}$-ATPase (SERCA). $\mathrm{Ca}^{2+}$ can also be extruded from the ASM cell by a second type of $\mathrm{Ca}^{2+}$ pump on the cell membrane, i.e. the plasmalemmal $\mathrm{Ca}^{2+}$-ATPase. Once again, to the extent that $\mathrm{Ca}^{2+}$ can be extruded from the cell, there must be an influx-uptake pathway which replaces the lost $\mathrm{Ca}^{2+}$ (without necessarily evoking a mechanical response), otherwise the cell will ultimately be depleted of $\mathrm{Ca}^{2+}$ and mechanical responsiveness will be lost. In addition to the voltage-dependent $\mathrm{Ca}^{2+}$-channels known to be present on the plasmalemma, and which may be important in refilling the internal $\mathrm{Ca}^{2+}$-pool $[45,46]$, there are several other influx pathways that have recently been identified in ASM. However, nonselective cation channels have been found and characterised in ASM [47-49]; these may include members of the transient receptor potential (TRP) family of channels, first discovered in the Drosophila visual transduction pathway, and which have subsequently been found on essentially every cell type where researchers have looked for them. More recently, an intriguing role for the $\mathrm{Na}^{+} / \mathrm{Ca}^{2+}$ exchanger (NCX) has been found for refilling of the internal $\mathrm{Ca}^{2+}$ store in ASM $[45,50]$. NCX has traditionally been viewed as an efflux pathway, using the energy stored within the transmembrane gradients for 


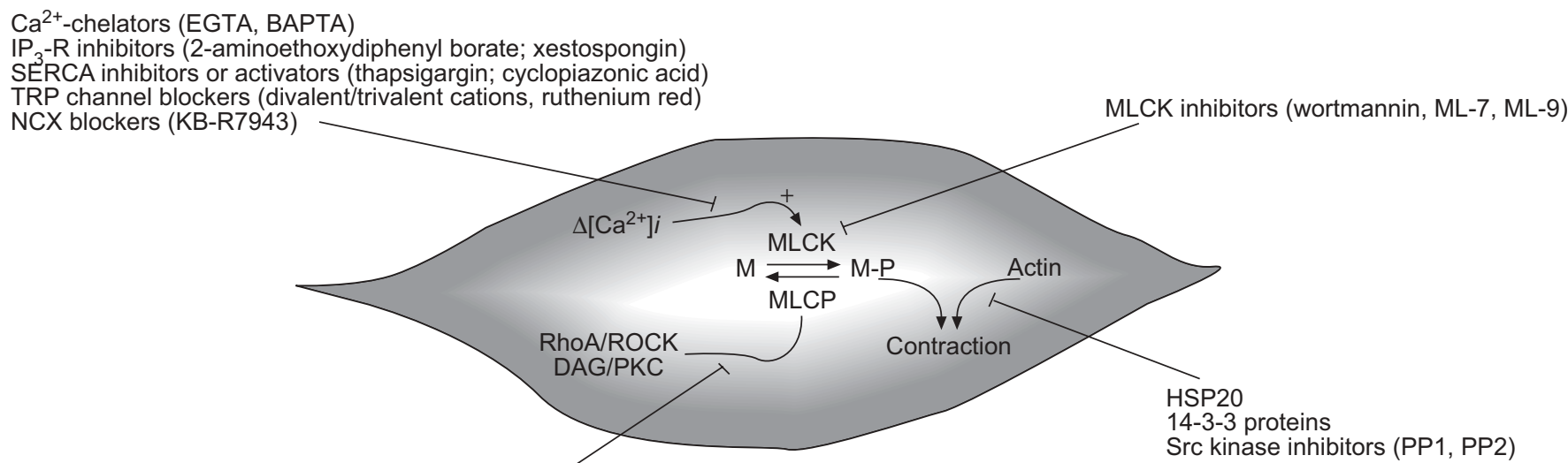

MLCP activators (telokin)

ROCK inhibitors (Y-27632, HA-1077)

PKC inhibitors (chelerythrine, calphostin)

Src family kinase inhibitors (PP1, PP2)

Tyrosine kinase inhibitors (genistein, tyrphostin)

FIGURE 3. The convergent signalling pathway centres around the phosphorylation state of myosin, which in turn is the determinant of actin-myosin interaction (i.e. contraction). This involves phosphorylation of myosin by myosin light chain kinase (MLCK; regulated by changes in $\left[\mathrm{Ca}^{2+}\right]_{i}$ ) and dephosphorylation by myosin light chain phosphatase (MLCP; regulated by RhoA/ROCK and/or protein kinase C (PKC)). In turn, all of these then provide novel targets for the treatment of asthma. M: myosin; P: phosphate; DAG: diacylglycerol; EGTA: ethylene glycol tetraacetic acid; BAPTA: 1,2-bis (aminophenoxy) ethane- $N, N_{,}, N^{\prime}, N^{\prime}$-tetraacetic acid; IP ${ }_{3}-R$ : inositol $1,4,5-$ trisphosphate receptor; TRP: transient receptor potential; NCX: Na ${ }^{+} \mathrm{Ca}^{2+}$ exchanger; ML-7: ML-9: src: HSP20: heat shock protein 20.

$\left[\mathrm{Na}^{+}\right]$and membrane potential to extrude $\mathrm{Ca}^{2+}$ against its own concentration gradient. However, during excitation, the membrane becomes depolarised and the $\left[\mathrm{Na}^{+}\right]$gradient decreases (due to influx of $\mathrm{Na}^{+}$through nonselective cation channels and its accumulation in diffusionally restricted spaces underneath the plasmalemma) such that the driving force on $\mathrm{Ca}^{2+}$ is now inward. The NCX operates in "reverse-mode" to now serve as a high-capacity influx pathway to refill the store which triggered the entire excitatory response.

Altogether, these various pumps, channels and exchangers work together to produce the $\mathrm{Ca}^{2+}$ oscillations, the frequency of which appears to be the direct signal transduced by the contractile apparatus [36, 37, 40, 41]. As yet it is unclear whether it is MLCK itself and/or myosin light chain phosphatase (MLCP) that actually sense $\mathrm{Ca}^{2+}$-wave frequency.

Whereas MLCK catalyses the phosphorylation of myosin and thereby triggers ASM contraction, MLCP is the enzyme responsible for undoing these changes. As such, MLCP is clearly expected to be important in bronchodilation. Surprisingly, however, it is now recognised to also be central to bronchoconstriction. That is, even at rest, there is an ongoing MLCP activity which constantly opposes the actions of MLCK. However, spasmogens trigger certain signalling events which suppress MLCP activity, thereby increasing the net amount of myosin phosphorylation for a given amount of $\mathrm{Ca}^{2+}$ signal, i.e. increasing the $\mathrm{Ca}^{2+}$ sensitivity of the contractile apparatus. At least two signalling pathways mediate this spasmogenic regulation of MLCP: 1) RhoA-activated kinase (ROCK), which directly phosphorylates MLCP and inactivates it; and 2) protein kinase $C$ (in turn activated by diacylglycerol generated within the phosphoinositide signalling cascade), which acts through CPI-17, an endogenous inhibitor of MLCP.
Finally, given that interaction between both actin and myosin is necessary and sufficient for contraction, it goes without saying that interfering with actin structure/function can have important effects upon excitation-contraction coupling. It is now known that acetylcholine can alter actin function [51], although the physiological relevance of these changes is still being explored. There is no information as to whether other noncholinergic agonists also act in this way.

\section{Novel targets for asthma based on this convergent signalling pathway}

Thus, altogether, contraction of ASM is triggered by phosphorylation of ASM by MLCK (which in turn is dependent upon $\mathrm{Ca}^{2+}$-oscillation frequency) and perhaps also by ROCK, and is often amplified by inhibition of MLCP by RhoA/ROCK and diacylglycerol/protein kinase $C$ (PKC). Armed with this knowledge it is now possible to propose novel treatments for asthma, just as it was possible to propose the existing classes of bronchodilators based on a pharmacological understanding of the excitatory and inhibitory inputs to the ASM. In each case, reference will be made to compounds or techniques that are currently available to achieve these goals experimentally (fig. 3), to reassure readers that control of those cellular targets is already feasible and not some futuristic dream. However, many of these compounds are not yet ready for clinical use against asthma (e.g. they are too toxic or too nonspecific). It is now necessary to modify/adapt them, or identify better alternatives, for actual use in the clinical setting.

First, it may be possible to interfere with the $\mathrm{Ca}^{2+}$ oscillations themselves, which trigger the excitatory events. This can be achieved experimentally by loading the cells with $\mathrm{Ca}^{2+}$ chelators, which buffer the changes in $\left[\mathrm{Ca}^{2+}\right]_{i}$ (including ethylene glycerol tetraacetic acid or 1,2-bis (aminophenoxy) 
ethane- $\mathrm{N}, \mathrm{N}, \mathrm{N},{ }^{\prime}, \mathrm{N}^{\prime}$-tetraacetic acid) by inhibiting $\mathrm{Ca}^{2+}$ release through the $\mathrm{IP}_{3}$ receptors (e.g. using 2-aminoethoxydiphenyl borate or xestospongin), or by increasing SERCA activity and / or expression. However, it is possible to deplete the internal $\mathrm{Ca}^{2+}$ store within minutes using agents which inhibit SERCA activity (cyclopiazonic acid or thapsigargin) or inhibit the influx pathways that bring external $\mathrm{Ca}^{2+}$ in to refill the sarcoplasmic reticulum: experimentally, these include inhibitors of the NCX (KB-R7943), calcium channels (nifedipine) or nonselective cation channels (SKF36965, gadolinium, maitotoxin, azaspiracid-4).

Secondly, MLCK itself might be targeted, since it is ultimately responsible for the change leading to bronchoconstriction. Several inhibitors of MLCK activity are available experimentally, including ML-7, ML-9 and wortmannin.

Thirdly, MLCP provides a tantalising target. It may be possible to directly increase its activity: telokin is an endogenous protein that appears to regulate MLCP activity, thereby providing a possible handhold on this enzyme. Alternatively, it is possible to interfere with the signalling pathways which limit MLCP activity: ROCK can be inhibited using agents such as Y-27632 or HA-1077, while PKC can be inhibited by selective inhibitors too numerous to list here. Upstream from these, RhoA can be inhibited (using cytotoxic necrotising factor) and the phosphoinositide cascade subverted using phopholipase C inhibitors (U73122).

Tyrosine kinase inhibitors may prove to be highly useful. Many excitatory cellular events in ASM are highly sensitive to nonspecific tyrosine kinase inhibitors (e.g. genistein, tyrphostin) or to those which are selective for Src-kinase (e.g. PP1, PP2) [52-67]. The specific role(s) for these tyrosine kinase(s) are very poorly understood, but clearly include signalling events pertaining to actin filaments [68-71]. Several potential key players are emerging as this field develops, including heat shock proteins and 14-3-3 proteins [51].

Finally, rather than merely interfering with certain aspects of ASM function, we now know it is possible to eliminate the ASM itself and thereby treat asthma: bronchial thermoplasty involves heat delivered to the airway such that the mass of smooth muscle in the bronchial wall is markedly reduced [7275]. At bronchoscopy and under local anaesthesia, radiofrequency energy is delivered via a four-armed basket electrode that is expanded to contact the airway wall and the airway wall is warmed to a target temperature of $65^{\circ} \mathrm{C}$. When the resulting thermal injury resolves, over 3-6 weeks, the treated tissue appears normal except that the muscle content is reduced by $\sim 50 \%$ (as such, this directly addresses the airway remodelling that accompanies asthma and which is not treated by any pharmacological approach). This is associated with reduced potential for bronchoconstriction. The benefit to patients with asthma persists for years; the first patient was treated in 2000 and is still experiencing benefit. In clinical trials, patients with mild, moderate and severe asthma have been successfully treated, demonstrating persistent improvement in asthma control and quality of life. The adverse events associated with bronchial thermoplasty were encountered in the peri-treatment period; there were no long-term adverse outcomes, such as progressive tissue changes or airway injury.
One limitation of this approach is that only those airways which are accessible by a bronchoscope can be treated, and each must be treated one at a time. However, the success of this approach offers proof-of-principle that ablating the ASM per se is useful, and it might be possible to overcome both limitations using a molecular approach, which would allow one to treat all airways, including the smallest ones, simultaneously. For example, a silver bullet approach could be taken in which a toxin is coupled to an antibody that specifically recognises some membrane marker unique to ASM cells, much as is currently done for certain cancers. Alternatively, a Trojan horse approach is possible in which RNA vectors are developed that are preferentially expressed within ASM cells and unload some type of cytotoxic or inhibitory protein. Finally, with a better understanding of the mechanisms underlying migration, apoptosis and/or proliferation in ASM [76], it might be possible to decrease their numbers by interfering with these normal cellular processes.

\section{Concerns about these novel approaches}

Although several interesting targets are emerging as potentially exploitable in novel therapies for asthma, there are still some fairly significant roadblocks before us. Perhaps the biggest of these is that many of the targets put forward (fig. 3) will also have an effect on the pulmonary vasculature, and could act beyond that to exert systemic effects. However, this has always been a problem for pharmacological therapies for asthma. It must have been daunting to suggest that it might be possible to treat this disease using anticholinergics, given the importance of the vagal/parasympathetic innervation in nearly every organ of the body, or to do so using phosphodiesterase inhibitors given that every cell type employs this enzymatic activity. However, those hurdles were circumvented in the past in several ways.

First, the drugs could be delivered by inhalation so that the first cells to encounter them would be the airway epithelium and ASM, ensuring rapid onset of action and high local bioavailability. If reasonably low concentrations were used, the pulmonary vasculature would be less affected and systemic effects even less so.

Secondly, by investigating in detail the nature of the specific targets involved, it was possible to identify isotypes or subtypes which were present in ASM but were not relevant (or were less so) in the pulmonary vasculature and beyond. For example, the first anticholinergics were selective antimuscarinics (obviating any effects through nicotinic acetylcholine receptors), and then were further restricted to have selectivity against muscarinic $\mathrm{M}_{2}$ or $\mathrm{M}_{3}$ receptors. Likewise, histamine receptors were confined to those having selectivity for histaminergic $\mathrm{H}_{1}$ receptors, and phosphodiesterase inhibitors to the PDE4 or PDE5 subtypes.

It may be possible to use the same strategies to focus on the novel targets proposed above: to look for subtypes of MLCK (or ROCK, SERCA, NCX, TRP channels or MLCP) which are expressed in ASM but not the pulmonary vasculature. However, very little is known about the possible existence of subtypes of these enzymes in ASM. Unfortunately, few in the airway field are studying MLCK, MLCP, SERCA or ROCK at this level of molecular detail, in part because others are doing 
so using other types of smooth muscle. However, until this changes we will never know if it is possible to selectively regulate these ASM enzymatic activities.

\section{CONCLUSIONS}

An accumulated wealth of data has led to the development of five fundamentally different pharmacological approaches for the treatment of asthma which target (at least in part) the ASM, these are: 1) anticholinergics; 2) antihistamines; 3) antileukotrienes; 4) $\beta$-agonists; and 5) PDE inhibitors. However, asthma is still not fully controlled, and we have not seen substantially new molecules become available to resolve this problem. This may be a result, in part, of the fact that previous and ongoing experiments may not be designed optimally (an over emphasis on cholinergic responses, use of nonhuman and/or tracheal preparations, or use of overwhelming concentrations of pharmacological agents, rather than physiologically-relevant and therapeutically-achievable ones). However, it is felt that another major contributor to this drought is the lack of resources being allocated to basic research of ASM physiology, particularly the mechanisms underlying excitation-contraction coupling.

The present study has highlighted the potential benefits (and risks) of five new targets for asthma therapy: 1) disrupting $\mathrm{Ca}^{2+}$ oscillations; 2) inhibiting myosin light chain kinase; 3) stimulating myosin light chain phosphatase; 4) modulating actin signalling; or 5) reducing airway smooth muscle mass itself. Clearly a great deal of research remains to be done before these possibilities can be exploited in asthma.

\section{REFERENCES}

1 Solway J, Forsythe SM, Halayko AJ, Vieira JE, Hershenson MB, Camoretti-Mercado B. Transcriptional regulation of smooth muscle contractile apparatus expression. Am J Respir Crit Care Med 1998; 158: S100-S108.

2 Janssen LJ. Isoprostanes: an overview and putative roles in pulmonary pathophysiology. Am J Physiol Lung Cell Mol Physiol 2001; 280: L1067-L1082.

3 Janssen LJ, Catalli A, Helli P. The pulmonary biology of isoprostanes. Antioxid Redox Signal 2005; 7: 244-255.

4 Janssen LJ, Premji M, Netherton S, et al. Excitatory and inhibitory actions of isoprostanes in human and canine airway smooth muscle. J Pharmacol Exp Ther 2000; 295: 506511.

5 Barnes PJ. Clinical studies with calcium antagonists in asthma. Br J Clin Pharmacol 1985; 20: Suppl. 2, 289S-298S.

6 Fish JE. Calcium channel antagonists in the treatment of asthma. J Asthma 1984; 21: 407-418.

7 Gordon EH, Wong SC, Klaustermeyer WB. Comparison of nifedipine with a new calcium channel blocker, flordipine, in exercise-induced asthma. J Asthma 1987; 24: 261-265.

8 Hoppe M, Harman E, Hendeles L. The effect of inhaled gallopamil, a potent calcium channel blocker, on the latephase response in subjects with allergic asthma. J Allergy Clin Immunol 1992; 89: 688-695.

9 Middleton E Jr. The treatment of asthma - beyond bronchodilators. N Engl Reg Allergy Proc 1985; 6: 235-237.

10 Riska H, Stenius-Aaniala B, Arvi AR. Comparison of the efficacy of an ACE-inhibitor and a calcium channel blocker in hypertensive asthmatics. A preliminiary report. Postgrad Med J 1986; 62: Suppl. 1, 52-53.

11 Sly PD, Olinsky A, Landau LI. Does nifedipine affect the diurnal variation of asthma in children? Pediatr Pulmonol 1986; 2: 206-210.

12 Trian T, Benard G, Begueret H, et al. Bronchial smooth muscle remodeling involves calcium-dependent enhanced mitochondrial biogenesis in asthma. J Exp Med 2007; 204: 3173-3181.

13 Cook NS, Chapman ID. Therapeutic potential of potassium channel openers in peripheral vascular disease and asthma. Cardiovasc Drugs Ther 1993; 7: Suppl. 3, 555-563.

14 Faurschou P, Mikkelsen KL, Steffensen I, Franke B. The lack of bronchodilator effect and the short-term safety of cumulative single doses of an inhaled potassium channel opener (bimakalim) in adult patients with mild to moderate bronchial asthma. Pulm Pharmacol 1994; 7: 293297.

15 Kidney JC, Fuller RW, Worsdell YM, Lavender EA, Chung KF, Barnes PJ. Effect of an oral potassium channel activator, BRL 38227, on airway function and responsiveness in asthmatic patients: comparison with oral salbutamol. Thorax 1993; 48: 130-133.

16 Small RC, Berry JL, Burka JF, et al. Potassium channel activators and bronchial asthma. Clin Exp Allergy 1992; 22: 11-18.

17 Janssen LJ. Ionic mechanisms and $\mathrm{Ca}^{2+}$ regulation in airway smooth muscle contraction: do the data contradict dogma? Am J Physiol Lung Cell Mol Physiol 2002; 282: L1161-L1178.

18 Stephens NL. Airway smooth muscle. Lung 2001; 179: 333373.

19 Tolloczko B, Turkewitsch P, Choudry S, Bisotto S, Fixman ED, Martin JG. Src modulates serotonin-induced calcium signaling by regulating phosphatidylinositol $4,5-$ bisphosphate. Am J Physiol Lung Cell Mol Physiol 2002; 282: L1305-L1313.

20 Mitchell HW, Sparrow MP. The relevance of pharmacological dose-response curves to airway narrowing. Trends Pharmacol Sci 1989; 10: 488-491.

21 Catalli A, Janssen LJ. Augmentation of bovine airway smooth muscle responsiveness to carbachol, $\mathrm{KCl}$, and histamine by the isoprostane 8-iso-PGE 2 . Am J Physiol Lung Cell Mol Physiol 2004; 287: L1035-L1041.

22 Liu C, Tazzeo T, Janssen LJ. Isoprostane-induced airway hyperresponsiveness is dependent upon internal $\mathrm{Ca}^{2+}$ handling and Rho/ROCK signaling. Am J Physiol Lung Cell Mol Physiol 2006; 291: 1177-1184.

23 Gerthoffer WT. Agonist synergism in airway smooth muscle contraction. J Pharmacol Exp Ther 1996; 278: 800807.

24 Oguma T, Ito S, Kondo M, et al. Roles of P2X receptors and $\mathrm{Ca} 2+$ sensitization in extracellular adenosine triphosphateinduced hyperresponsiveness in airway smooth muscle. Clin Exp Allergy 2007; 37: 893-900.

25 Toescu EC. Temporal and spatial heterogeneities of $\mathrm{Ca}^{2+}$ signaling: mechanisms and physiological roles. Am J Physiol 1995; 269: G173-G185.

26 Koopman WJ, Scheenen WJ, Errington RJ, et al. Membraneinitiated $\mathrm{Ca}^{2+}$ signals are reshaped during propagation to subcellular regions. Biophys J 2001; 81: 57-65. 
27 Davis JP, Tikunova SB, Walsh MP, Johnson JD. Characterizing the response of calcium signal transducers to generated calcium transients. Biochemistry 1999; 38: 4235-4244.

28 Berridge MJ. The AM and FM of calcium signalling. Nature 1997; 386: 759-760.

29 Cartin L, Lounsbury KM, Nelson MT. Coupling of $\mathrm{Ca}^{2+}$ to CREB activation and gene expression in intact cerebral arteries from mouse: roles of ryanodine receptors and voltage- dependent $\mathrm{Ca}^{2+}$ channels. Circ Res 2000; 86: 760-767.

30 Putney JW Jr. Calcium signaling: up, down, up, down...what's the point? Science 1998; 279: 191-192.

31 Berridge MJ, Bootman MD, Lipp P. Calcium - a life and death signal. Nature 1998; 395: 645-648.

32 De Koninck P, Schulman H. Sensitivity of CaM kinase II to the frequency of $\mathrm{Ca}^{2+}$ oscillations. Science 1998; 279: 227-230.

33 Dupont G, Goldbeter A. CaM kinase II as frequency decoder of $\mathrm{Ca}^{2+}$ oscillations. Bioessays 1998; 20: 607-610.

34 Tompa P, Toth-Boconadi R, Friedrich P. Frequency decoding of fast calcium oscillations by calpain. Cell Calcium 2001; 29: 161-170.

35 Hajnoczky G, Csordas G, Madesh M, Pacher P. The machinery of local $\mathrm{Ca}^{2+}$ signalling between sarco-endoplasmic reticulum and mitochondria. J Physiol 2000; 529: 69-81.

36 Bai Y, Sanderson MJ. Airway smooth muscle relaxation results from a reduction in the frequency of $\mathrm{Ca} 2+$ oscillations induced by a cAMP-mediated inhibition of the $\mathrm{IP}_{3}$ receptor. Respir Res 2006; 7: 34.

37 Perez JF, Sanderson MJ. The frequency of calcium oscillations induced by $5-\mathrm{HT}, \mathrm{ACH}$, and $\mathrm{KCl}$ determine the contraction of smooth muscle cells of intrapulmonary bronchioles. J Gen Physiol 2005; 125: 535-553.

38 Dolmetsch RE, Xu K, Lewis RS. Calcium oscillations increase the efficiency and specificity of gene expression. Nature 1998; 392: 933-936.

39 Li W, Llopis J, Whitney M, Zlokarnik G, Tsien RY. Cellpermeant caged InsP3 ester shows that $\mathrm{Ca}^{2+}$ spike frequency can optimize gene expression. Nature 1998; 392: 936-941.

40 Bergner A, Sanderson MJ. Acetylcholine-induced calcium signaling and contraction of airway smooth muscle cells in lung slices. J Gen Physiol 2002; 119: 187-198.

41 Bergner A, Sanderson MJ. Airway contractility and smooth muscle $\mathrm{Ca}^{2+}$ signaling in lung slices from different mouse strains. J Appl Physiol 2003; 95: 1325-1332.

42 Hirota S, Helli P, Janssen LJ. Ionic mechanisms and $\mathrm{Ca}^{2+}$ handling in airway smooth muscle. Eur Respir J 2007; 30: 1400-1419.

43 Hirota SA, Janssen LJ. Sodium and asthma: something borrowed, something new? Am J Physiol Lung Cell Mol Physiol 2007; 293: L1369-L1373.

44 Tazzeo T, Zhang Y, Keshavjee S, Janssen LJ, Ryanodine receptors decant internal $\mathrm{Ca}^{2+}$ store in human and bovine airway smooth muscle. Eur Respir J 2008; 32: 275-284.

45 Hirota S, Janssen LJ. Store-refilling involves both L-type $\mathrm{Ca}^{2+}$ channels and reverse-mode $\mathrm{Na}^{+} / \mathrm{Ca}^{2+}$ exchange. Eur Respir J 2007; 30: 269-278.

46 Janssen LJ, Sims SM. Emptying and refilling of $\mathrm{Ca}^{2+}$ store in tracheal myocytes as indicated by ACh-evoked currents and contraction. Am J Physiol 1993; 265: C877-C886.
47 Fleischmann BK, Wang YX, Kotlikoff MI. Muscarinic activation and calcium permeation of nonselective cation currents in airway myocytes. Am J Physiol 1997; 272: C341C349.

48 Wang YX, Fleischmann BK, Kotlikoff MI. $\mathrm{M}_{2}$ receptor activation of non-selective cation channels in smooth muscle cells: calcium and $\mathrm{G}_{\mathrm{i}} / \mathrm{G}_{\mathrm{o}}$ requirements. $A m \mathrm{~J}$ Physiol 1997; 273: C500-C508.

49 Janssen LJ, Sims SM. Acetylcholine activates non-selective cation and chloride conductances in canine and guinea-pig tracheal myocytes. J Physiol 1992; 453: 197-218.

50 Hirota S, Pertens E, Janssen LJ. The reverse mode of the $\mathrm{Na}^{+} / \mathrm{Ca}^{2+}$ exchanger provides a source of $\mathrm{Ca}^{2+}$ for store refilling following agonist-induced $\mathrm{Ca}^{2+}$ mobilization. Am J Physiol Lung Cell Mol Physiol 2007; 292: L438-L447.

51 Gerthoffer WT, Gunst SJ. Invited review: focal adhesion and small heat shock proteins in the regulation of actin remodeling and contractility in smooth muscle. J Appl Physiol 2001; 91: 963-972.

52 Janssen LJ, Wattie J, Lu-Chao H, Tazzeo T. Muscarinic excitation-contraction coupling mechanisms in tracheal and bronchial smooth muscles. J Appl Physiol 2001; 91: 1142-1151.

53 Abe MK, Chao TS, Solway J, Rosner MR, Hershenson MB. Hydrogen peroxide stimulates mitogen-activated protein kinase in bovine tracheal myocytes: implications for human airway disease. Am J Respir Cell Mol Biol 1994; 11: 577-585.

54 Conway AM, Rakhit S, Pyne S, Pyne NJ. Platelet-derivedgrowth-factor stimulation of the p42/p44 mitogen-activated protein kinase pathway in airway smooth muscle: role of pertussis-toxin-sensitive G-proteins, c-Src tyrosine kinases and phosphoinositide 3-kinase. Biochem J 1999; 337: 171-177.

55 Hirshman CA, Zhu D, Pertel T, Panettieri RA, Emala CW. Isoproterenol induces actin depolymerization in human airway smooth muscle cells via activation of an Src kinase and GS. Am J Physiol Lung Cell Mol Physiol 2005; 288: L924L931.

56 Krymskaya VP, Goncharova EA, Ammit AJ, et al. Src is necessary and sufficient for human airway smooth muscle cell proliferation and migration. FASEB J 2005; 19: 428-430.

57 Krymskaya VP, Orsini MJ, Eszterhas AJ, et al. Mechanisms of proliferation synergy by receptor tyrosine kinase and $G$ protein-coupled receptor activation in human airway smooth muscle. Am J Respir Cell Mol Biol 2000; 23: 546-554.

58 Lew DB, Dempsey BK, Zhao Y, Muthalif M, Fatima S, Malik KU. $\beta$-hexosaminidase-induced activation of p44/42 mitogen-activated protein kinase is dependent on p21Ras and protein kinase $\mathrm{C}$ and mediates bovine airway smoothmuscle proliferation. Am J Respir Cell Mol Biol 1999; 21: 111-118.

59 Page K, Li J, Hodge JA, et al. Characterization of a Rac1 signaling pathway to cyclin $\mathrm{D}(1)$ expression in airway smooth muscle cells. J Biol Chem 1999; 274: 22065-22071.

60 Pertel T, Zhu D, Panettieri RA, Yamaguchi N, Emala CW, Hirshman CA. Expression and muscarinic receptor coupling of Lyn kinase in cultured human airway smooth muscle cells. Am J Physiol Lung Cell Mol Physiol 2006; 290: L492-L500. 
61 Porcelli AM, Ghelli A, Hrelia S, Rugolo M. Phospholipase D stimulation is required for sphingosine-1-phosphate activation of actin stress fibre assembly in human airway epithelial cells. Cell Signal 2002; 14: 75-81.

62 Rakhit S, Conway AM, Tate R, Bower T, Pyne NJ, Pyne S. Sphingosine 1-phosphate stimulation of the p42/p44 mitogen-activated protein kinase pathway in airway smooth muscle. Role of endothelial differentiation gene 1, c-Src tyrosine kinase and phosphoinositide 3- kinase. Biochem J 1999; 338: 643-649.

63 Rakhit S, Pyne S, Pyne NJ. The platelet-derived growth factor receptor stimulation of $\mathrm{p} 42 / \mathrm{p} 44$ mitogen-activated protein kinase in airway smooth muscle involves a Gprotein-mediated tyrosine phosphorylation of Gab1. Mol Pharmacol 2000; 58: 413-420.

64 Simon AR, Takahashi S, Severgnini M, Fanburg BL, Cochran BH. Role of the JAK-STAT pathway in PDGFstimulated proliferation of human airway smooth muscle cells. Am J Physiol Lung Cell Mol Physiol 2002; 282: L1296L1304.

65 Smith PG, Garcia R, Kogerman L. Mechanical strain increases protein tyrosine phosphorylation in airway smooth muscle cells. Exp Cell Res 1998; 239: 353-360.

66 Tolloczko B, Tao FC, Zacour ME, Martin JG. Tyrosine kinase-dependent calcium signaling in airway smooth muscle cells. Am J Physiol Lung Cell Mol Physiol 2000; 278: L1138-L1145.

67 Zacour ME, Tolloczko B, Martin JG. Calcium and growth responses of hyperresponsive airway smooth muscle to different isoforms of platelet-derived growth factor (PDGF). Can J Physiol Pharmacol 2000; 78: 867-873.
68 Mehta D, Tang DD, Wu MF, Atkinson S, Gunst SJ. Role of Rho in $\mathrm{Ca}^{2+}$-insensitive contraction and paxillin tyrosine phosphorylation in smooth muscle. Am J Physiol Cell Physiol 2000; 279: C308-C318.

69 Tang D, Mehta D, Gunst SJ. Mechanosensitive tyrosine phosphorylation of paxillin and focal adhesion kinase in tracheal smooth muscle. Am J Physiol 1999; 276: C250-C258.

70 Tang DD, Wu MF, Opazo Saez AM, Gunst SJ. The focal adhesion protein paxillin regulates contraction in canine tracheal smooth muscle. J Physiol 2002; 542: 501-513.

71 Wang Z, Pavalko FM, Gunst SJ. Tyrosine phosphorylation of the dense plaque protein paxillin is regulated during smooth muscle contraction. Am J Physiol 1996; 271: C1594-C1602.

72 Cox PG, Miller J, Mitzner W, Leff AR. Radiofrequency ablation of airway smooth muscle for sustained treatment of asthma: preliminary investigations. Eur Respir J 2004; 24: 659-663.

73 Danek CJ, Lombard CM, Dungworth DL, et al. Reduction in airway hyperresponsiveness to methacholine by the application of RF energy in dogs. J Appl Physiol 2004; 97: 1946-1953.

74 Cox G, Thomson NC, Rubin AS, et al. Asthma control during the year after bronchial thermoplasty. $N$ Engl J Med 2007; 356: 1327-1337.

75 Pavord ID, Cox G, Thomson NC, et al. Safety and efficacy of bronchial thermoplasty in symptomatic, severe asthma. Am J Respir Crit Care Med 2007; 176: 1185-1191.

76 Trian T, Benard G, Begueret H, et al. Bronchial smooth muscle remodeling involves calcium-dependent enhanced mitochondrial biogenesis in asthma. J Exp Med 2007; 204: 3173-3181. 